T. 2, № 2, 2020

М. А. Яцун

Національний університет “Львівська політехніка”, кафедра

e-mail:Yacunma@gmail.com

\title{
ІМПУЛЬСНЕ ДІАГНОСТУВАННЯ ТЕХНІЧНОГО СТАНУ СИЛОВИХ ТРАНСФОРМАТОРІВ ЗА ХАРАКТЕРИСТИКАМИ ВЛАСНИХ ЗАГАСНИХ КОЛИВАНЬ
}

https://doi.org/

(C) Яиун M. A., 2020

Викладено спосіб імпульсного дефектографування силового трансформатора за збудження у ньому власних загасних коливань періодичними імпульсами постійної напруги. За величиною зміни параметрів цих коливань під час експлуатації трансформатора можна оцінити виникнення дефектів шляхом періодичного діагностування та порівняння дефектограм із нормограмами та прогнозувати ровиток дефектів і встановити можливість подальшої експлуатації трансформатора без необхідності поточного чи капітального ремонту.

Ключові слова: імпульсне дефектографування, силовий трансформатор, загасні коливання, параметри коливань, дефекти.

\section{Постановка проблеми}

Силовий трансформатор (СТ) $є$ одним 3 найважливіших вузлів електричної станції або підстанції (ПС). Для енергосистеми України характерна наявність значної кількості ПС, обслуговування і ремонт обладнання яких проводить оперативно-виїзна бригада підприємства електричних мереж. Особливо актуальним в зв'язку з цим стає своєчасне виявлення розвитку дефектів обмоток СТ, яке дозволяє вивести СТ в ремонт перш ніж трапиться аварія, пов'язана з виходом його з ладу.

До розвитку дефектів належать міжвиткові короткі замикання (МКЗ), деформація обмоток, ослаблення їх пресування. Ці дефекти, як правило, $є$ наслідком коротких замикань на лініях електропередач (ЛЕП), що живляться від цього СТ, або перевантаженнями СТ. МКЗ призводять до локального нагрівання обмоток і навколишнього масла, що призводить до прискореного старіння ізоляції. Деформація обмоток призводить до механічного пошкодження ізоляції, що провокує появу МКЗ і часткових розрядів. Ослаблення пресування обмоток призводить до посилення їх вібрації, а отже до прискореного зносу як ізоляції, так і елементів кріплення.

Аналіз останніх досліджень

На ринку діагностичної апаратури є доволі велика кількість пристроїв [1-10], число яких відповідає числу методів діагностики. Тому повний комплект діагностичної апаратури володіє таким істотним недоліком, як висока вартість. Також недоліком слід вважати те, що велика кількість різних за типом і принципом дії пристроїв діагностики представляє певні труднощі для експлуатаційного персоналу. 


\section{M. А. Яиун}

Застосовувані методи діагностики силових трансформаторів вимагають роботи безпосередньо на досліджуваному об'єкті, через що є недостатньо оперативними, бо вимагають виїзду персоналу на об'єкт. Крім того, ряд методів вимагає значного часу для аналізу (наприклад, методи аналізу проб трансформаторного масла) або дорогого устаткування (наприклад, метод тепловізійного контролю). Також це має достатньо універсальних методів діагностики.

На сьогоднішній день попит на діагностичну апаратуру визначається такими вимогами: дешевизна, універсальність, точність, компактність пристрою і простота його експлуатації. Одним 3 методів, які найповніше відповідають зазначеним вище вимогам, може бути метод частотних характеристик, оснований на частотних властивостях СТ, бо трансформатор - реактивний елемент з індуктивним характером опору.

\section{Виклад основного матеріалу.}

Суть методу полягає в тому, що на одну з обмоток трансформатора через послідовно ввімкнений конденсатор $C$ подається імпульс напруги (зондуючий імпульс) і одночасно осцилографується напруга на вимірювальному опорі $R_{\text {н }}$, ввімкненому в одну із фаз другої обмотки (рис. 1). Вимірювання проводять періодично. Порівняння попередніх і наступних записаних осцилограм, зокрема до короткого замикання (к.з.) (нормограми) і наступних після к.з. (дефектограми), дає змогу оцінити результат випробування. Зміни в дефектограмах свідчать про появу електричних або механічних пошкоджень.

За імпульсної дії заступна схема багатосекційної обмотки трансформатора складається 3 послідовно-паралельного сполучення ємностей між окремими котушками, ємностей на землю, індуктивностей окремих котушок та їхніх взаємних індуктивностей (активними опорами котушок нехтують). Зміна цих ємностей та індуктивностей внаслідок появи дефектів (виткових замикань, зміщення котушок або витків) спотворює імпульс струму в досліджуваній обмотці, що $є$ причиною зміни осцилограми.

На рис. 1 подано схему діагностування технічного стану силового трифазного трансформатора із параметрами короткого замикання. На схемі обмотка нижчої напруги трансформатора 3 послідовно до неї ввімкненим конденсатором С збуджуються періодично постійною напругою. Тоді в колі цієї обмотки 3 конденсатором протікають загасаючі коливання, які через взаємну індуктивність трансформуються у відповідні коливання в обмотці вищої напрги. Тут для підвищення вихідного сигналу інформативною $є$ обмотка вищої напруги, яка замкнена на опір $\mathrm{R}_{\mathrm{H}} 3$ індикатором інформативної напруги $U_{2}$.

У диференційній схеми вимірювань (рис. 1,6 ) досліджувані напруги знімаються не з одного, а відразу 3 двох опорів $R_{н}$, ввімкнених в дві фази обмотки, і подаються на диференційний підсилювач осцилографа. Через ідентичність фаз трансформатора ці напруги незначно відрізняються між собою і різниця між ними мала, що дає змогу підсилити ії ще в декілька разів і у стільки ж разів підвищити чутливість вимірювань порівняно з однофазною схемою (рис. $1, a$ ).

Висока чутливість імпульсного методу, яка набагато перевищує всі відомі методи індикації пошкоджень, а також відносна простота і можливість проводити вимірювання на повністю зібраному трансформаторі зробили перспективним його застосування для діагностування трансформаторів під час їх випробування, після транспортування і під час експлуатації.

Оптимальними $\epsilon$ постійна напруга чи прямокутний (або близький до нього за формою) імпульс тривалістю 0,5-1 мкс, бо вони не впливають суттєво на форму вихідного сигналу. При короткому зондувальному імпульсі зменшується амплітуда збуджуваних в обмотках трансформатора коливань; збільшення ж тривалості імпульсу мало впливає на зростання амплітуди коливань і невигідне 3 енергетичного погляду. 


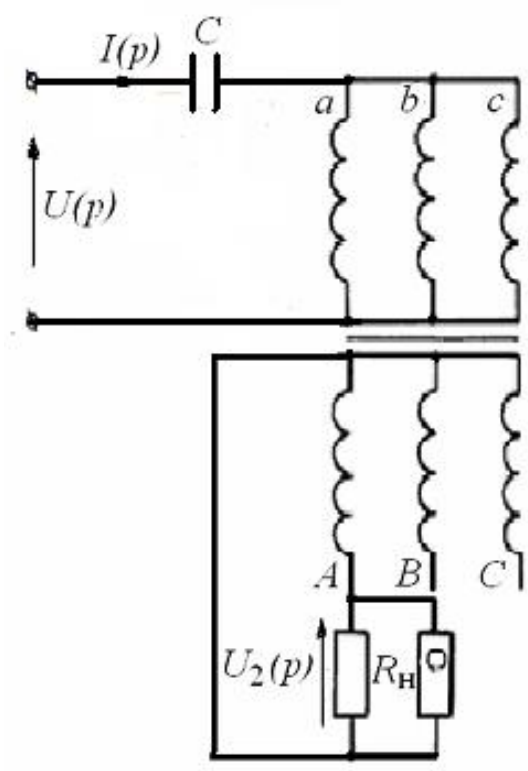

$a$

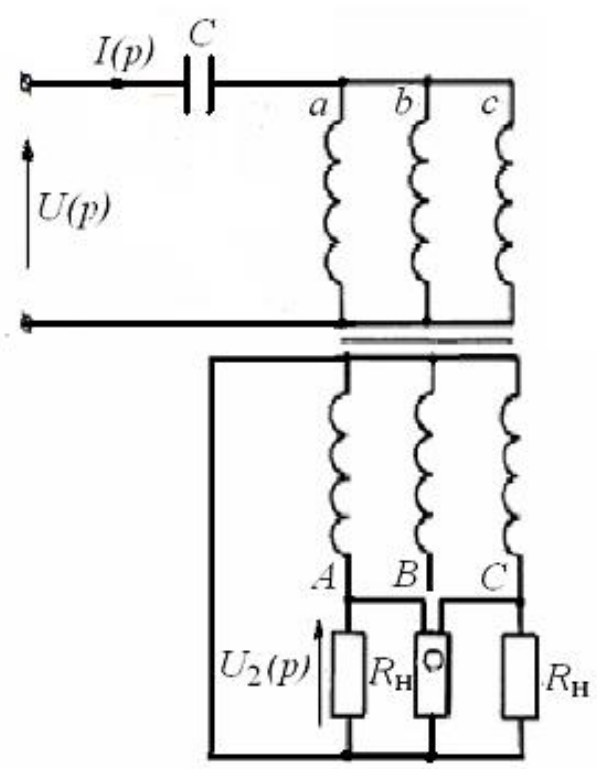

$\sigma$

Рис.1. Принцииова схема при імпульсному дефектографуванні трифазного трансформатора $a$-однофазна; $\sigma$ - диференційна

Амплітуду зондувальних імпульсів вибирають у межах 500-1000 $B$ переважно залежно від чутливості диференційного підсилювача і від типу досліджуваного трансформатора, а також від ступеня дії завад на вимірну схему та якості ії комутуючих елементів.

Осцилограми вихідних напруг являють собою високочастотні загасаючі коливання , пов'язані переважно $з$ власними і взаємною індуктивностями обмоток трансформатора і ємністю в колі збудження.

Для визначення стану випробуваного трансформатора застосовують принцип послідовного дефектографування, який полягає в тому, що осцилографування виконують періодично, зокрема після кожного к.з., включаючи і налагоджувальні. Отже, криву досліджувальної напруги знімають двічі на дві різні осцилограми: для попереднього діагностування вона $є$ дефектограмою, а для наступного - нормограмою. Послідовне дефектографування має ту перевагу, що дає можливість слідкувати за динамікою зміни технічного стану трансформатора протягом всього процесу випробувань і експлуатації.

Під час дефектографування трифазних трансформаторів за диференційною схемою зондуючий імпульс подається на одну з обмоток симетрично, тобто так, щоб з двох фаз вторинної або первинної обмоток можна було отримати ідентичні сигнали. Тоді найзручнішими є схеми, в яких зондуючий імпульс подається на всі три фази будь-якої обмотки одночасно (рис. 1, б). Можна також подавати імпульс через нейтраль. Аналогічні вимоги до місця подачі зондуючого імпульсу і при імпульсному дефектографуванні однофазних трансформаторів.

Впровадження імпульсного дефектографування, зокрема при випробуванні трансформаторів на електродинамічну стійкість і під час експлуатації дозволяє випробувати всі трансформатори в баку, значно скоротити обсяг допоміжних вимірювань, точніше визначити результат випробувань, припинити випробування, не доводячи трансформатор до руйнування.

Якщо нехтувати поздовжніми і поперечними ємностями в самому трансформаторі порівняно iз вхідною ємністю і прийняти, що під час діагностування магнітна система трансформатора ненасичена, то за постійної напруги збуджкення можна отримати аналітичний вираз вихідного сигналу. 


\section{M. А. Яиун}

Нехтуючи також гілкою намагнічування у заступній схемі трансформатора, за схемою на рис. 1 для перетвореної за Лапласом вихідної напруги маємо:

$$
\mathrm{U}_{2}(\mathrm{p})=\frac{\mathrm{U}(\mathrm{p}) \mathrm{R}_{\mathrm{H}}}{\mathrm{Z}(\mathrm{p})}
$$

де

$$
\mathrm{U}(\mathrm{p})=\mathrm{A} / \mathrm{p} ; \quad \mathrm{Z}(\mathrm{p})=\mathrm{R}_{\mathrm{K}}+\mathrm{R}_{\mathrm{H}}+\mathrm{pL}+\frac{1}{\mathrm{pC}} ; \quad \mathrm{I}(\mathrm{p})=\frac{\mathrm{pAC}}{\mathrm{p}\left[\mathrm{p}^{2} \mathrm{LC}+\mathrm{pC}\left(\mathrm{R}_{\mathrm{K}}+\mathrm{R}_{\mathrm{H}}\right)+1\right]} ;
$$

$\mathrm{U}(\mathrm{p})=\mathrm{A}\left(1-\mathrm{e}^{-\mathrm{p}}\right) / \mathrm{p}$ - зображення за Лапласом прямокутного імпульсу висотою (амплітудою) A $\mathrm{i}$ тривалістю $\tau ; \mathrm{R}_{\mathrm{k}} \mathrm{i} \mathrm{L}_{\mathrm{k}}$ - відповідно активний опір $\mathrm{i}$ індуктивність короткого замикання трансформатора; $\mathrm{L}_{\mathrm{k}}=\mathrm{X}_{\mathrm{k}} / 314 ; \mathrm{X}_{\mathrm{k}}-$ індуктивний опір короткого замикання трансформатора; $\mathrm{R}_{\mathrm{H}}^{\prime}$ - активний опір навантаження трансформатора, зведений до обмотки збудження; $\mathrm{I}_{1}(\mathrm{p})$ перетворений за Лапласом струм в обмотці збудження трансформатора.

Тоді за теоремою розкладу Хевісайда для вихідної напруги на навантаженні $\mathrm{R}_{\mathrm{H}}^{\prime}$, зведеної до обмотки збудження і перетвореної за Лапласом, у випадку зондувального імпульсу в формі постійної напруги, коли $\mathrm{U}(\mathrm{p})=\mathrm{A} / \mathrm{p}$, одержимо:

$$
u_{2}(t)=\frac{A R_{H}}{\omega L} e^{-\alpha t} \sin (\omega t),
$$

де

$$
\omega=\sqrt{\left[\frac{1}{\mathrm{LC}}-\frac{\left(\mathrm{R}_{\mathrm{K}}+\mathrm{R}_{\mathrm{H}}\right)^{2}}{4 \mathrm{~L}^{2}}\right]} ; \quad \alpha=\frac{\mathrm{R}_{\mathrm{K}}+\mathrm{R}_{\mathrm{H}}}{2 \mathrm{~L}} .
$$

Для більшої інформативності вихідної напруги ємність у вхідному колі необхідно вибрати такої величини, щоб забезпечити коливний загасний процес, бо тоді інформативними параметрами є: амплітуда, частота та коефіцієнт загасання. Тривалість збуджувального імпульсу повинна забезпечити протікання перехідного процесу.

Для наочності на рис. 2 представлений графік зміни вихідної напруги трансформатора для таких значень величин і параметрів у схемі на рис. 1:

$\mathrm{A}=1000 \mathrm{~B} ; \tau=10^{-6} \mathrm{c} ; \mathrm{R}_{\mathrm{L}}=10000$ Ом; $\mathrm{C}=10^{-8} \Phi ; \mathrm{R}_{\mathrm{K}}=5 \mathrm{OM} ; \mathrm{X}_{\mathrm{K}}=50 \mathrm{OM} ; \mathrm{L}_{\mathrm{k}}=\mathrm{X}_{\mathrm{K}} / 314 ; \mathrm{R}_{\mathrm{H}}=$ 1000 Oм.

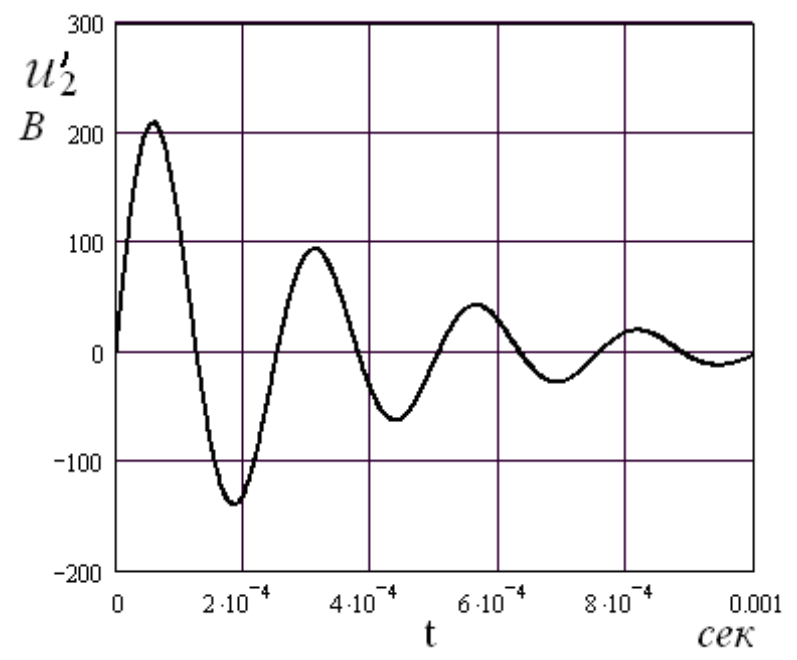

Рис.2. Перехідна напруга на вторинній обмотиі трансформатора 


\section{Висновки}

Запропоновано метод визначення технічного стану силових трансформаторів під час збудження первинної обмотки постійною напругою через увімкнений послідовно конденсатор. Тоді за амплітудою, частотою та коефіцієнтом загасання інформативною $є$ напруга на вторинній обмотці у формі загасних коливань.

Представлено принципову схему діагностування, яка включає ємність, схему трифазного трансформатора і вимірний блок для однофазного та диференційного аналізу. Отриманий вираз для перетвореної за Лапласом інформаційної напруги на вихідному навантаженні трансформатора в формі раціональної функції. Перехід до оригіналу (миттєвого значення вихідної напруги) проведений за теоремою розкладу Хевісайда. Поданий графік загасних коливань вихідної напруги для заданих значень параметрів вимірної схеми. У загальному випадку, зокрема за прямокутного імпульсу збудження, числове обернення перетворення Лапласа можна провести за відомими способами, викладеними в літературі $[11,12]$.

\section{Список використаних джерел}

1. Построение схем мониторинга электрооборудования / Комков Е. Ю., Сизов О.Н., Капустин С. А. // Тезисы докладов международной научно-технической конференции: Состояние и перспективы развития электротехнологии. Т. 2. Иваново, 2005. Наукові записки, вип. 10, част.II 255

2. Лизунов С. Д., Лоханин А. К. Проблемы современного трансформирования в России / Электричество. - Москва, 2000. № 9.

3. Шутенко О. В. Исследование влияния загрузки трансформатора на состояние масла в процессе эксплуатации / Вестник НТУ «ХПИ». Электроэнергетика и преобразовательная техника. Харьков: НТУ «ХПИ», 2004. № 7 .

4. Шутенко О. В. Формирование однородныхх массивов показателей качества трансформаторного масла в условиях априорной неопределенности результатов испытаний/Интегрированные технологии и энергосбережение. - Харьков: НТУ «ХПИ», 2006. № 4.

5. Бондаренко В. Е., Щапов П. Ф., Шутенко О. В. Повышение эффективности эксплуатационного измерительного контроля трансформаторных масел. Харьков: НТУ «ХПИ», 2007.

6. Хренников А. Ю., Киков О. М. Диагностика силовых трансформаторов в Самараэнерго методом низковольтных импульсов // Электрические станщии. № 112003.

7. Хренников А. Ю., Шлегель О. А., Запорожеи М. И. Диагностика повреждений силовых трансформаторов, находящихся в эксплуатачии на ТЭЦ Волжского Автозавода в г. Тольятти / Электрические станщии, 1994.

8. Хренников А.Ю.,Шлегель О. А. Диагностика повреждений и методика обработки результатов измерений силовых трансформаторов при испытаниях и в эксплуатаиии / Электротехника, 1997.

9. Хренников А. Ю., Передельский В. А., Сафонов А. А., Якимов В. А. Опьт диагностики дефектов и повреждений силовых трансформаторов, накопленный в ЗАО “ДИАРОСТ" // Сборник докладов Регионального Совета по диагностике электрооборудования при Уралэнерго. Екатеринбург, 16-17 сентября 2003. бюл. 19.

10. Яиун М. А. Експлуатаиія та діагностування електричних машин і трансформаторів: навч. посіб. Львів: Видавнищтво Наџіонального університету «Львівська політехніка», 2003. -180 с.

11.Яиун М. А., Яиун А. М. Наближене чисельне обернення перетворення Лапласа аперіодичних перехідних величин при неруйнівному контролі імпульсним вихрострумовим методом // Вісн. Наи. ун-ту «Львівська політехніка». 2009. № 654 . С. 285-290.

12. Яиун М. А., Яиун А. М., Шуплат О. І. Наближена числова реалізація зворотного перетворення Лапласа загасаючих коливань у разі неруйнівного контролю імпульсним вихрострумовим методом // Вісн. Наи. ун-ту «Львівська політехніка». 2010. № 671. С. 140-146.

\section{References}

1. Postroenye skhem monytorynha эlektrooborudovanyia / Komkov E. Iu., Syzov O. N., Kapustyn S. A. // Tezysbl dokladov mezhdunarodnoi nauchno-tekhnycheskoi konferentsyy: Sostoianye y perspektyvy razvytyia эlektrotekhnolohyy. T. 2. Yvanovo, 2005. Naukovi zapysky, vyp. 10, chast. II 255 


\section{M. А. Яиун}

2. Lyzunov S. D., Lokhanyn A. K. Problemy sovremennoho transformyrovanyia v Rossyy // Elektrychestvo. Moskva, 2000. No 9.

3. Shutenko O. V. Yssledovanye vlyianyia zahruzky transformatora na sostoianye masla $v$ protsesse эkspluatatsyy // Vestnyk NTU «KhPY». Elektroenerhetyka y preobrazovatelnaja tekhnyka. Kharkov: NTU «KhPY», 2004. No 7.

4. Shutenko O. V. Formyrovanye odnorodnykh massyvov pokazatelej kachestva transformatornoho masla $v$ uslovyiakh apryornoi neopredelennosty rezultatov yspytanyi /Yntehryrovannye tekhnolohyy y enerhosberezhenye. Kharkov: $N T U$ «KhPY», 2006. № 4 .

5. Bondarenko V. E., Shchapov P. F., Shutenko O. V. Povyshenye effektyvnosty ekspluatatsyonnoho yzmerytelnoho kontrolia transformatornykh masel. Kharkov: NTU «KhPY», 2007.

6. Khrennykov A. Iu., Kykov O. M. Dyahnostyka sylovykh transformatorov v Samaraenerho metodom nyzkovoltnykh ympulsov /Elektrycheskye stantsyy. № 112003.

7. Khpennykov A. Iu., Shlehel O. A., Zapopozhets M. Y. Dyahnostyka povrezhdenyi sylovykh transformatorov, nakhodiashchykhsia v ekspluatatsyy na TETs Volzhskoho Avtozavoda v h.Toliatty /Elektpycheskye stantsyy, 1994.

8. Khpennykov A. Iu.Shlehel O. A. Dyahnostyka povrezhdenyi y metodyka obrabotky rezultatov yzmerenyi sylovykh transformatorov pry yspytanyiakh y $v$ эkspluatatsyy / Elektrotekhnyka, 1997.

9. Khrennykov A. Iu., Peredelskyi V. A., Safonov A. A., Yakymov V. A. Opyt dyahnostyky defektov y povrezhdenyi sylovykh transformatorov, nakoplennyj v ZAO "DYAROST" // Sbornyk dokladov Rehyonalnoho Soveta po dyahnostyke elektrooborudovanyia pry Uralэnerho. Ekaterynburh, 16-17 sentiabria 2003. biul.19.

10. Jacun M. A. Ekspluatatsiia ta diahnostuvannia elektrychnykh mashyn i transformatoriv: Navch. Posibnyk. Lviv: Vydavnytstvo Natsionalnoho universytetu «Lvivska politekhnika», 2003. $-180 \mathrm{~s}$.

11.Jacun M. A., Jacun A. M. Nablyzhene chyselne obernennia peretvorennia Laplasa aperiodychnykh perekhidnykh velychyn pry neruinivnomu kontroli impulsnym vykhrostrumovym metodom // Visn. NU «Lvivska politekhnika». 2009. № 654 . S. 285-290.

12. Jacun M. A., Yacun A. M., Shuplat O. I. Nablyzhena chyslova realizatsiia zvorotnoho peretvorennia Laplasa zahasajuchykh kolyvan u razi neruinivnoho kontroliu impulsnym vykhrostrumovym metodom // Visn. NU «Lvivska politekhnika». 2010. № 671. S. 140-146.

M. A. Yatsun

Національний університет “Львівська політехніка", кафедра e-mail: Yacunma@gmail.com

\section{IMPULSIVE DIAGNOSTICATING OF THE TECHNICAL STATE POWER TRANSFORMERS ON DESCRIPTIONS OF DAMPED OSCILLATIONS}

(C) Yatsun M. A., 2020

The expounded method of impulsive expose of defect of power transformer at excitation in him of damped oscillations by the periodic impulses of constant voltage. On the size of change of parameters of these vibrations at exploitation of transformer it is possible to estimate the origin of defects by the periodic diagnosticating and comparison of defectograms with normograms and to forecast development of defects and define possibility of after exploitation of transformer without the necessity of permanent or capital repair.

Keywords: impulsive expose of defect, power transformer, damped oscillations, parameters of oscillations, defects 